\title{
Estrategias y comunicación: cómo dar malas noticias
}

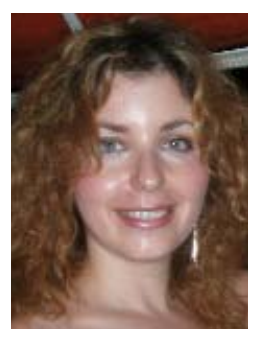

Elena González-Guerra Unidad de Dermatología. Hospital Infanta Cristina. Parla. Madrid.

\section{INTRODUCCIÓN}

Según el abogado y escritor romano del siglo II Aulus Gellius, el médico completo es el médico humanista, o lo que es lo mismo, el que está capacitado en las tres dimensiones básicas del ser humano: pideia (educación), philanthropía (empatía) y techné (competencia técnica) ${ }^{1}$. Sin embargo, en la actualidad, la mayoría de los médicos, excluyendo tal vez a los psiquiatras, carecemos de una formación específica sobre la empatía en los momentos más delicados del ejercicio médico.

Se puede definir como «mala noticia» aquella que modifica radical y negativamente la idea que el paciente se ha hecho de su porvenir o el de una persona querida por él. La fuerza de la impresión recibida puede generar un sufrimiento añadido, innecesario en la persona que lo recibe, así como un deterioro en la relación médico-paciente posterior. El médico se anticipa a la situación y se estresa. De esta forma, el paciente recibe el estrés de su propio diagnóstico y el estrés que el médico le transmite. La relación médico-paciente se establece de forma viciosa, generando un círculo recíproco de ansiedad. Para romper ese círculo, o mejor, para evitar que aparezca, hay que utilizar correctamente dos elementos: la información y la comunicación.

En dermatología, son frecuentes estas situaciones de difícil asunción (neoplasias malignas, genodermatosis, psoriasis, alopecia areata, etc.) (fig. 1).

\section{OBJETIVO}

El objetivo de este texto es mostrar una serie de ideas o sugerencias sobre cómo comunicar malas noticias y seguramente defraude a todo el que pretenda encontrar una fórmula mágica.

\section{LA INFORMACIÓN}

Hasta hace pocos años, la información que se transmitía al paciente se regía por el principio de beneficencia o paternalismo. Esto es, el médico decidía qué debía conocer el paciente, en función de su propio criterio. Se podía así ocultar al enfermo el estado real de su enfermedad, los riesgos que corría o el pronóstico que le correspondía. Sin embargo, en la actualidad, la información se rige por el principio de autonomía, esto es, el paciente decide acerca de todo lo que se refiere a su enfermedad y debe dejar constancia de su conocimiento y aceptación en el caso de pruebas o tratamientos con riesgos, en el documento, ya instituido de forma general, del consentimiento informado ${ }^{2}$. Por tanto, dar una mala noticia es un acto ético. Pero además es un hecho médico. La justicia ha establecido que incumbe al médico revelar la información pertinente de forma justa, 


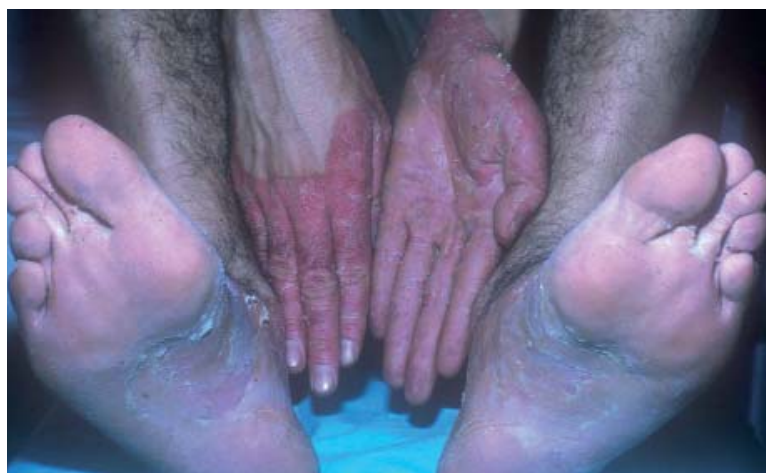

Figura 1. Queratodermia palmoplantar de Greither. Las enfermedades crónicas suponen un grave impacto en la calidad de vida. Una adecuada comunicación puede ayudar a la comprensión y aceptación de la enfermedad.

acerca de todos los hechos que afecten a los derechos e intereses del paciente. Finalmente, dar una mala noticia es un acto legal. Hay leyes que lo exigen, como el Código Civil o el artículo décimo de la Ley General de Sanidad, donde se dice: «El paciente tiene derecho a que se le dé, en térmicos comprensibles, a él y a sus familiares o allegados, información completa y continuada, verbal y escrita sobre su proceso, incluyendo el diagnóstico, pronóstico y alternativas de tratamiento». Esta nueva forma de enfrentarse con la información tiene, no obstante, sus riesgos. A menudo se explican detalles negativos de forma exhaustiva, casi con encarnizamiento, dejando al paciente sumido en una profunda depresión, nada favorecedora de su estado de salud. Todavía existe el privilegio de retener información en ciertos casos sobre algún dato que arriesgue la recuperación de un paciente inestable, temperamental o gravemente deprimido ${ }^{3}$ y por rechazo del enfermo. No se puede olvidar que, junto a la ley del derecho a la información, camina la del derecho a no ser informado (tabla 1).

\section{LA COMUNICACIÓN}

La acción comunicativa es, en sí misma, un proceso complejo en el que dos o más personas se relacionan y, a través de un intercambio de mensajes con código similar, tratan de comprenderse e influirse de forma que sus objetivos seas aceptados en la for- ma prevista, utilizando para ello un canal que actúa como soporte de la transmisión de la información.

Esta comunicación está llena de dificultades o ruidos:

- Dificultades propias del emisor: la codificación se ve dificultada por la conveniencia o inconveniencia social de lo que se quiere decir, por las expectativas sobre la reacción del otro, por el obstáculo que supone la comprensión del contenido, por el tecnicismo de la expresión, etc.

- Dificultades propias del canal de transmisión: por ejemplo, las diferencias entre una comunicación cara a cara, donde el $70 \%$ del mensaje se transmite con la expresión, las postura, etc., o la comunicación telefónica dependiente exclusivamente de la palabra.

- Dificultades propias del receptor: tras recibir el mensaje, depositado por el emisor en el canal adecuado, el receptor debe ser capaz de descodificarlo e interpretarlo apropiadamente. El conjunto de experiencias y conocimientos previos de quien recibe el mensaje, los sesgos de atención, los prejuicios, las expectativas, mediatizan el resultado.

\section{LA COMUNIC ACIÓN COMO CONDUCTA}

Los componentes conductuales de la comunicación son los que pueden ser observados por cualquier persona, esté implicada o no en el proceso comunicativo que se está llevando a cabo. Se pueden identificar tres componentes:

- Comunicación verbal: lo fundamental es la palabra, que se estructura en un nivel cognitivo. Los elementos más importantes son el contenido, la intención, la atención, las preguntas y las respuestas.

- Comunicación no verbal: utiliza otros elementos, como la sonrisa, otros gestos, la mirada, la expresión de la cara, la postura, la distancia frente al interlocutor, etc. Su función es tan importante que supone alrededor del $70 \%$ de la comunicación. Muchas veces el lenguaje no verbal contradice abiertamente lo que se está diciendo verbalmente, mientras que, en otras ocasiones, lo enfatiza. 
Tabla 1. Principales puntos de la Ley 41/2002, ley básica reguladora de la autonomía del paciente y de los derechos y obligaciones en materia de información y documentación clínica.

1. Derecho a la información sanitaria.

Los pacientes tienen derecho a conocer, con motivo de cualquier actuación en el ámbito de su salud, toda la información disponible sobre la misma, salvando los supuestos exceptuados por la Ley. Además toda persona tiene derecho a que se respete su voluntad de no ser informada.

La información, como regla general, se proporcionará verbalmente y comprende como mínimo la finalidad y naturaleza de cada intervención, sus riegos y sus consecuencias. Se dejará constancia de ella en la historia clínica. La información clínica será verdadera, se comunicará al paciente de forma comprensible y adecuada a sus necesidades y le ayudará a tomar decisiones de acuerdo con su propia y libre voluntad.

El titular del derecho a la información es el paciente. También serán informadas las personas vinculadas a él por razones familiares o de hecho, en la medida en que el paciente lo permita de manera expresa o tácita. El paciente será informado, incluso en caso de incapacidad, de modo adecuado a sus posibilidades de comprensión, cumpliendo con el deber de informar también a su representante legal.

Cuando el paciente, según el criterio del médico que le asiste, carezca de capacidad para entender la información a causa de su estado físico o psíquico, la información se pondrá en conocimiento de las personas vinculadas a él por razones familiares o de hecho.

El derecho a la información sanitaria de los pacientes puede limitarse por la existencia acreditada de una necesidad terapéutica. Se entenderá por necesidad terapéutica la facultad del médico para actuar profesionalmente sin informar antes al paciente, cuando por razones objetivas el conocimiento de su propia situación pueda perjudicar su salud de manera grave. Llegado este caso, el médico dejará constancia razonada de las circunstancias en la historia clínica y comunicará su decisión a las personas vinculadas al paciente por razones familiares o de hecho.

2. Derecho a la intimidad.

Toda persona tiene derecho a que se respete el carácter confidencial de los datos referentes a su salud y que nadie pueda acceder a ellos sin previa autorización amparada por la Ley.

3. Respeto a la autonomía del paciente. Consentimiento informado.

Toda actuación en el ámbito de la salud de un paciente necesita el consentimiento libre y voluntario del afectado. El consentimiento será verbal por regla general. Sin embargo, se prestará por escrito en los siguientes casos: intervención quirúrgica, procedimientos diagnósticos y terapéuticos invasores y, en general, aplicación de procedimientos que supongan riesgos o inconvenientes de notoria y previsible repercusión negativa sobre la salud del paciente.

La renuncia del paciente a recibir información está limitada por el interés de la salud del propio paciente, de terceros, de la colectividad y por las exigencias terapéuticas del caso. Los facultativos podrán llevar a cabo las intervenciones clínicas indispensables a favor de la salud del paciente, sin necesidad de contar con el paciente, en los siguientes casos: riesgo para la salud pública, riesgo inmediato grave para la integridad física o psíquica del paciente y cuando no sea posible contar con su autorización, se consultará, si las circunstancias lo permiten, a sus familiares o a personas vinculadas por razones de hecho a él.

Se otorgará consentimiento por representación en los siguientes supuestos:

1. Cuando el paciente no sea capaz de tomar decisiones, a criterio del médico responsable de la asistencia, o su estado físico o psíquico no le permita hacerse cargo de la situación. Si el paciente carece de representante legal, el consentimiento lo prestarán las personas vinculadas a él por razones familiares o de hecho.

2. Cuando el paciente esté incapacitado legalmente.

3. Cuando el paciente menor de edad no sea capaz intelectual, ni emocionalmente de comprender el alcance de la intervención. En este caso, el consentimiento lo dará el representante legal del menor después de haber escuchado su opinión, si tiene 12 años cumplidos.

4. No cabe prestar el consentimiento por representación en menores no incapaces ni incapacitados, pero emancipados o con 16 años cumplidos. Sin embargo, en caso de actuación de grave riesgo, según el criterio del facultativo, los padres serán informados y su decisión será tenida en cuenta para la toma de decisión correspondiente.

5. La interrupción voluntaria del embarazo y la práctica de técnicas de reproducción humana asistida se rigen por lo establecido con carácter general sobre la mayoría de edad (18 años).

- Comunicación paraverbal: se refiere más a la forma que al contenido, esto es, un paralenguaje que modifica la palabra, como el tono, el volumen o el silencio, y que se estructura a nivel emocional.

\section{ESTRATEGIAS}

El primer paso y más importante es estar absolutamente seguro de la información que vamos a trasmitir basándonos en datos objetivos. Existen distintos protocolos de actuación. El denominado 
consenso de Kalamazoo ${ }^{4}$, celebrado en el año 2001, estableció siete objetivos de la entrevista clínica, tras la discusión y acuerdo de los principales expertos en comunicación. Éstos eran: 1) construir una relación; 2) abrir una discusión o diálogo; 3) obtener información; 4) entender la perspectiva del paciente; 5) compartir información; 6) llegar a acuerdos en los problemas y los planes; 7) cierre y toma de precauciones.

El primero de ellos puede que sea el más importante. La relación construida dominará el conjunto de la comunicación.

Walter F. Baile y Robert Buckman (oncólogos) elaboraron un protocolo de actuación, escalonado en pasos, con el propósito de guiar con éxito al profesional en su entrevista con el paciente. Estas etapas deben ser recorridas en orden y al ritmo que marque el paciente, sin pasar de uno a otro hasta que no acabe el anterior: 1) preparar un entorno; 2) qué sabe el paciente; 3) qué y cuánto quiere saber: 4) información; 5) apoyo al paciente/familia; 6) plan de cuidados.

Consensuando ambas guías, se considera que la forma más favorable de comunicarse con un paciente es aquella en la que se dan las siguientes circunstancias (tabla 2):

1. Preparación de un entorno. Debe ser un ambiente tranquilo. La posición ha de ser cómoda y próxima al paciente.

2. ¿Qué sabe el paciente? Es preciso conocer qué idea previa tiene el paciente acerca de su enfermedad, qué más quiere saber y cuáles son sus preocupaciones y expectativas. Por ejemplo, puede saber ya que va a morir y lo que le preocupa es si antes quedará inútil mentalmente; o necesita conocer el tiempo aproximado que le queda de vida para arreglar su situación económica; o si podrá viajar a un lugar donde siempre quiso ir; o si podrá mantener relaciones sexuales, y tantas otras inquietudes que a veces no sospechamos. La información no será igual en cada caso y deberá centrarse en los intereses del paciente, más que en la meticulosidad científica.
3. ¿Qué y cuánto quiere saber? Debemos recordar que, paralelo al derecho a la información, discurre el derecho a no ser informado.

4. Información y comunicación. Todo comportamiento insertado en una relación asume valores de comunicación.

- Como norma general, se deben evitar las palabras de difícil comprensión y los tecnicismos, salvo que a continuación se aclare su significado. Durante la entrevista, se debe verificar a intervalos la comprensión: «... ¿̇me sigue?...».

- Comunicación no verbal. La mirada ha de ser directa, a los ojos, pero no fija, que pueda amedrentar. Debe existir seriedad, pero no severidad. El tono de voz medio, con voz firme, que no resulte autoritaria, ni tampoco temblorosa. No dar sensación de prisa.

\section{Apoyo al paciente/familia:}

- Exploración de la enfermedad. Exploración de las vivencias que ocasiona. Es conveniente favorecer la expresión de sentimientos, escuchando atentamente al paciente si nos interrumpe. Escuchar sin convertirse en juez ni moralista, simplemente escuchar, incluso los silencios, es un ejercicio altamente eficaz en la comunicación humana.

- Exploración de las relaciones familiares y laborales. Saber si trabaja cara al público, si sus compañeros lo aíslan, si tiene padres que se preocupan o se desentienden de su salud y sus preocupaciones, etc.

- No se puede ignorar la postura de la familia en este campo. Existe un tipo de familia que podríamos llamar abstencionista, que se comporta como simple espectadora de la situación. No colabora, pero tampoco crea problemas a la hora de la información. Otras veces, se trata de una familia activa, que pregunta acerca de la enfermedad delante del paciente. Es frecuente que, ante la frase «tiene usted un tumor...», rápidamente los acompañantes pregunten si es malo, si está extendido, si le puede matar. Aquí es donde hay que recordar el derecho a no ser informado. No todos los 
Tabla 2. Estructura de la entrevista médico paciente: normas prácticas.

- Averiguar al comienzo qué sabe el paciente: «¿Cómo piensa que van las cosas?».

- Informar del estado de la situación evitando tecnicismos: «La mancha que hemos analizado...».

- Utilizar frases cortas, que son más fácilmente comprensibles y recordables: «Esta enfermedad no es contagiosa».

- Valerse de términos positivos: «De todas formas, los ganglios no están afectados». Crónico en lugar de incurable, importante en lugar de agresivo, etc.

- Razonar conjuntamente con el paciente: «¿Comprende cómo el sol pone moreno? Pues la radioterapia es otra radiación que también a veces oscurece la piel...».

- Verificar a intervalos la comprensión: «¿Me sigue», «¿comprende lo que le quiero decir?».

- Dejar una puerta abierta a la esperanza: «Podemos ir eliminando las zonas afectadas...».

- Manejar la incertidumbre, no dar plazos exactos: «El tiempo dirá cómo van las cosas...».

- Potenciar los recursos familiares: «Son ustedes una familia muy unida», «Me llama la atención cómo se preocupan sus hijos de usted...».

- Comprobar la asimilación: «¿Lo ha entendido todo?», «¿Puede repetírmelo?».

pacientes quieren saber lo que tienen. Son los que permanecen callados y doloridos mientras sus familiares preguntan. Siempre se les debe recordar a éstos que, de momento, responderemos a las preguntas del paciente, que es el interesado, y que en otro momento, si lo desean, después de la consulta, hablaremos con ellos. Esta respuesta amable, pero firme, suele ser efectiva. En el extremo opuesto, se encuentra la familia que ruega al médico que se le oculte al paciente su diagnóstico, que se le mienta francamente, para que no sufra. Basándose en el derecho a ser informado, si el paciente lo pide abiertamente, hay que informarle. Además, en el mejor de los casos, se puede omitir la verdad, pero nunca mentir. Debemos intentar potenciar los recursos familiares con frases como «Son ustedes una familia muy unida», «Me llama la atención cómo se preocupan de usted sus hijos»; evitar culpabilizar e informar sobre el apoyo social que existe, como las asociaciones de pacientes, etc.

6. Búsqueda de acuerdos. Si se hace de forma consensuada, participativa y realista, los resultados para la salud serán mucho mayores. Además, la llamada Ley de Autonomía del Paciente (ley 41/2002 de derechos y obligaciones en materia de información y documentación clínica) así lo recomienda. Las opciones deben ser consultadas con el enfermo, que colaborará en la decisión terapéutica más oportuna para él según su criterio y el consejo del especialista.

\section{CONCLUSIÓN}

La certeza de no poder curar en muchas ocasiones no significa que no se pueda ayudar. La comunicación adecuada, sin olvidar que es un proceso bidireccional médico-paciente y paciente-médico, puede ser la mejor, sino la única, herramienta terapéutica en muchas ocasiones. Y como tal herramienta, requiere aprendizaje.

\section{BIBLIOGRAFÍA}

1. García Campayo J, Aseguinolaza L, Tazón P. El desarrollo de las actitudes humanistas en medicina. Med Clin. 1998;111:23-6.

2. Iglesias Díez L, De Lorenzo y Montero R, Guerra Tapia A, Díaz Díaz R, Herrera Ceballos E. Información, consentimiento y documentación clínica en Dermatología. Madrid: Editores Médicos; 2005.

3. Shiffman MA. Fracaso en notificar al paciente resultados desfavorables en pruebas o diagnósticos. Int J Cosmetic Medicine Surgery. (Ed. en español) 2001;3:149-50.

4. Participants in the Bayer-Fetzer Conference on Physician-Patient communication in Medical Education. Essential elements of communication in medical encounters: the Kalamazoo Consensus Statement. Acad Med. 2001;76:390-3. 